\title{
Enantioselective Construction of the ABCDE Pentacyclic Core of the Strychnos Alkaloids
}

\author{
Adam D. Gammack Yamagata and Darren J. Dixon* \\ Department of Chemistry, Chemistry Research Laboratory, University of Oxford, Mansfield Road, Oxford, OX1 3TA \\ Supporting Information Placeholder
}

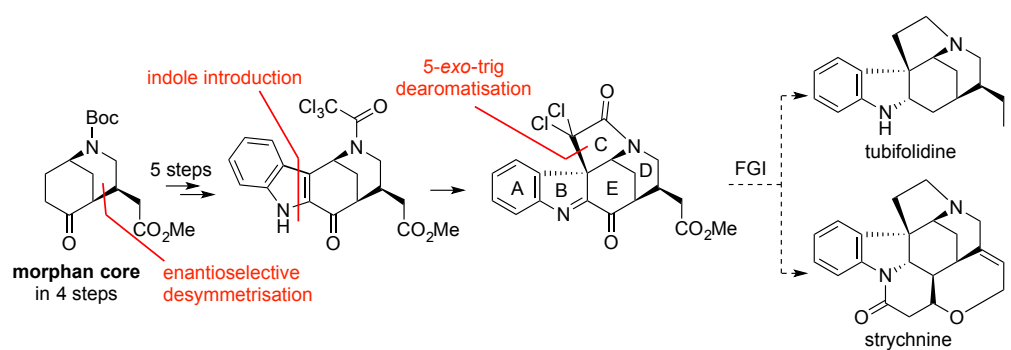

ABSTRACT: An efficient enantioselective 12 step synthesis to the ABCDE pentacyclic core of the Strychnos alkaloids is described. A key feature of this approach is an organocatalysed enantioselective desymmetrisation to generate the morphan core in high ee and dr. After palladium-catalysed installation of the indole moiety, a subsequent 5-exo-trig dearomatising atom transfer radical cyclisation was developed to construct the C-ring. Following a series of functional group interconversions, the pentacyclic amine core was obtained with all the relevant architecture including five stereocentres pertaining to the Strychnos alkaloids.

The Strychnos alkaloids encompass a large group of architecturally complex indole alkaloids of which strychnine is its most prominent member (Figure 1). Strychnine is a structurally dense alkaloid with many challenging features and, as such, has attracted significant interest from the synthetic community ever since it was first synthesised by Woodward in $1954 .{ }^{1}$ Many different strategies for the synthesis of strychnine, other Strychos alkaloids and their cores exist. ${ }^{2}$ All the Strychnos alkaloids posses the same common 6,5,5,6,6-pentacyclic ring system but differ about the N-1, C-16, and C-18 nodes.

Our strategy targeted a core structure with functional groups at carbons C-16 and C-18 that would allow access to a variety of these alkaloids after further synthetic manipulation.

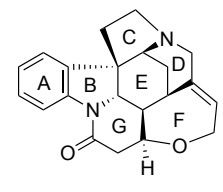

strychnine

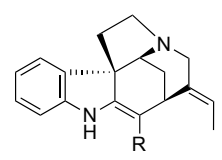

norfluorocurarin, $\mathrm{R}=\mathrm{CHO}$ akuammicine, $\mathrm{R}=\mathrm{CO}_{2} \mathrm{Me}$

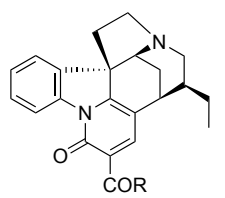
leuconicine $\mathrm{A}, \mathrm{R}=\mathrm{NH}_{2}$
leuconicine $\mathrm{B}, \mathrm{R}=\mathrm{OMe}$

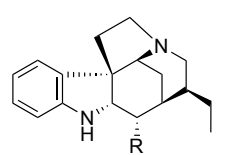

tubifolidine, $\mathrm{R}=\mathrm{H}$ geissoschizoline, $\mathrm{R}=\mathrm{CH}_{2} \mathrm{OH}$

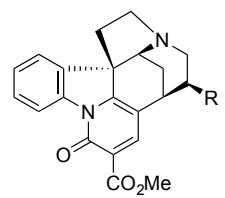

astoleucine $\mathrm{B}, \mathrm{R}=\mathrm{COCH}_{3}$ echitamidine, $\mathrm{R}=(\mathrm{S})-\mathrm{CH}(\mathrm{OH}) \mathrm{CH}_{3}$

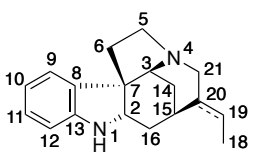

common pentacyclic core
Figure 1. A selection of the Strychnos alkaloids (Strychnan skeletal type with biogenetic numbering)
Scheme 1. Synthetic plan towards the Strychnos alkaloid core
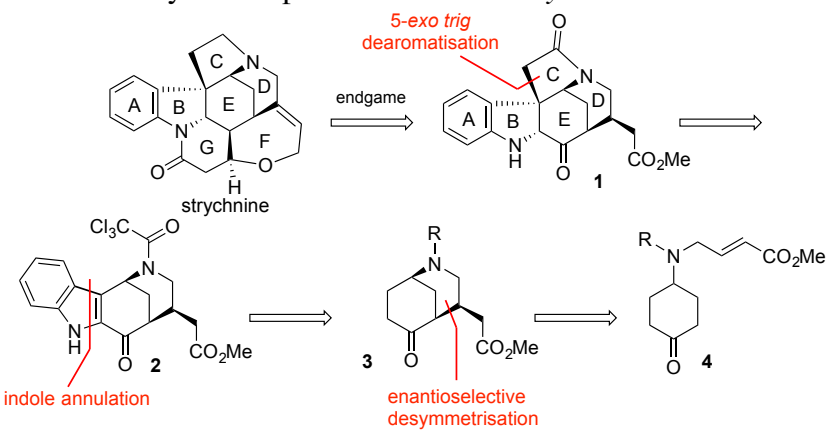

The synthesis of pentacyclic core 1 would rely on a key 5-exotrig dearomatising cyclisation of tetracyclic indole $2 .{ }^{3}$ In turn, tetracycle 2 would be synthesised by introduction of an indole moiety into enantioenriched morphan 3. Morphan 3 could be accessed in high ee and dr from prochiral cyclohexanone 4 using the organocatalysed enantioselective desymmetrisation reaction that we previously reported. ${ }^{4}$ We envisioned this synthetic route would quickly build the desired pentacyclic core $\mathbf{1}$ with the appropriate architecture relevant, not only to strychnine but other Strychnos alkaloids such as tubifolidine with an additional stereocenter at C-20.

Synthesis of prochiral substrate 7 was achieved in three steps starting from ketone 5 (Scheme 2). First, a reductive amination with methyl (E)-4-aminobut-2-enoate using $\mathrm{NaBH}_{3} \mathrm{CN}$ and TFA and subsequent acetal deprotection of the crude product using aqueous $\mathrm{HCl}$ in THF gave 6 , which was 
Scheme 2. Synthesis of the enantioenriched morphan core

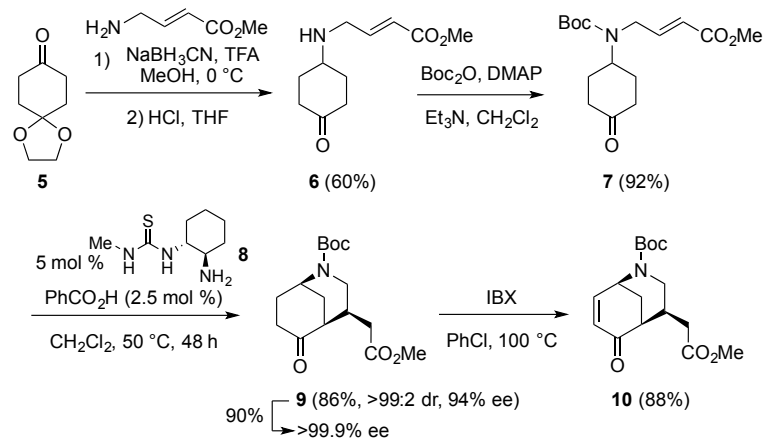

purified and $N$-Boc protected to afford desymmetrisation precursor 7 in good overall yield.

In our previously reported enantioselective desymmetrisation of prochiral cyclohexanones by organocatalytic intramolecular Michael additions to $\alpha, \beta$-unsaturated esters, a new and effective low-molecular-weight cyclohexanediamine-derived primary amine thiourea organocatalyst (8) was identified by computational studies and subsequently validated. ${ }^{4}$ Treatment of substrate 7 with organocatalyst $8(5 \mathrm{~mol} \%)$ and benzoic acid as co-catalyst in $\mathrm{CH}_{2} \mathrm{Cl}_{2}$ at $50{ }^{\circ} \mathrm{C}$ in a sealed vessel afforded morphan 9 with three stereogenic centers in $86 \%$ yield, $94 \%$ ee, and as a single diastereomer. Subsequent recrystallisation from refluxing methanol enhanced the ee to $>99.9 \%$ in an overall yield of $77 \%$ for both the cyclisation and recrystallisation steps. Oxidation to enone $\mathbf{1 0}$ was necessary for further functionalisation towards an indole moiety and proceeded in excellent yield using IBX in $\mathrm{PhCl}$ at $100{ }^{\circ} \mathrm{C}$.

Two methods were explored for installing the indole moiety into enone 10 (Scheme 3). The first consisted of coupling a 2 -nitroaryl group to the $\beta$-carbon of the enone and a subsequent reductive $N$-heteroannulation to complete the construction of the indole. To this end, the decarboxylative Heck reaction has been demonstrated to be a useful method for coupling 2-nitro aryl groups to olefins. ${ }^{5}$ However, bicyclic enone $\mathbf{1 0}$ was a challenging substrate for this reaction and after much optimisation, its reaction with 2-nitrobenzoic acid, $\mathrm{Pd}(\mathrm{TFA})_{2}$ as catalyst and $\mathrm{Ag}_{2} \mathrm{CO}_{3}$ as stoichiometric oxidant gave 11 in only $19 \%$ yield. Nonetheless, the reductive $N$-heteroannulation of $\mathbf{1 1}$ to give indole $\mathbf{1 2}$ proceeded in excellent yield using $\mathrm{CO}$ as the external reductant and with catalytic amounts of $\operatorname{Pd}(\mathrm{dba})_{2}, 1,10$-phen (1,10-phenantroline) ${ }^{6}$ and dppp (1,3bis(diphenylphosphino)propane). Overall, the combined yield of these two steps was $15 \%$, which was unacceptable and insufficient for generating large quantities of indole 12. As an alternative, the Barluenga indolisation of vinyl halides was explored. ${ }^{7}$ Bromination of enone $\mathbf{1 0}$ using bromine in $\mathrm{CH}_{2} \mathrm{Cl}_{2}$ at $0{ }^{\circ} \mathrm{C}$ and in situ $\mathrm{E} 1 \mathrm{cB}$ elimination using $\mathrm{Et}_{3} \mathrm{~N}$ afforded bromoenone $\mathbf{1 3}$ in excellent yield (Scheme 3). A subsequent screen of ligands in the $N$-vinylation reaction reaction of bromide 13 with 2-chloroaniline in the presence of $\mathrm{Pd}_{2}(\mathrm{dba})_{3}$ and $\mathrm{Cs}_{2} \mathrm{CO}_{3}$ in toluene at $110^{\circ} \mathrm{C}$ identified Brettphos as a good Pdligand for this transformation (see Supporting Information (SI) for the full screen of biaryl phosphane ligands). Indole $\mathbf{1 2}$ was obtained in $56 \%$ yield along with intermediate product 14 in $24 \%$ yield. It was possible to resubject isolated intermediate 14 to the cross-coupling conditions to afford more indole product 12 in $66 \%$ yield. Following this approach, the combined yield for the generation of indole $\mathbf{1 2}$ from enone $\mathbf{1 0}$ was
Scheme 3. Introduction of the indole moiety

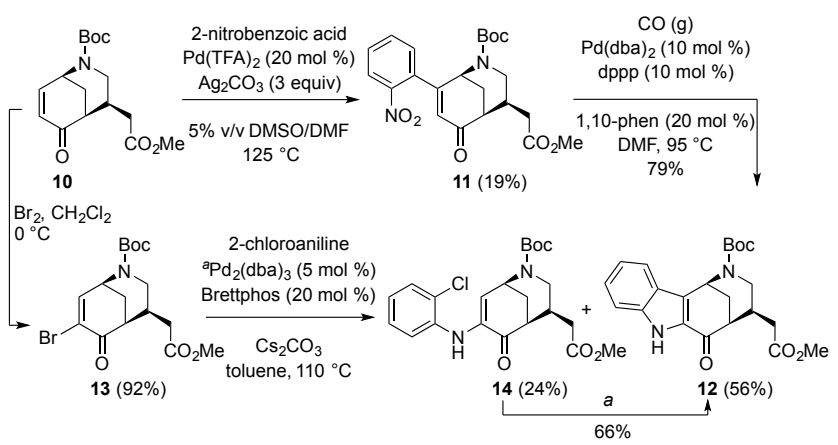

dramatically improved to $66 \%$. With indole intermediate 12 in hand, a method of C-ring closure was sought.

The synthesis of this ring in the Strychnos alkaloids from the ABDE-tetracycle has been previously reported using a cationic Pummerer ring closure of the electron rich indole onto a thionium ion derived from a dithiane. ${ }^{8}$ Initial attempts to use the same method for the synthesis of the C-ring were unsuccessful on our system and an alternative atom transfer radical cyclisation (ATRC) was developed (Scheme 4). ${ }^{9}$ The $N$-Boc group of 12 was exchanged for a reactive trichloroacetamide via treatment with TFA and $N$-acylation using trichloroacetyl chloride to give $\mathbf{2}$ ready for attempted $\mathrm{C}$-ring formation. Attempted cyclisation of $\mathbf{2}$ with $\mathrm{CuCl}$ and typical ligands ${ }^{10}$ for $\mathrm{Cu}(\mathrm{I})$ in ATRC reactions was unsuccessful and it was evident from color changes that $\mathrm{Cu}(\mathrm{I})$ was undergoing disproportionation/degradation. Whilst TBTA (16, tris[(1-benzyl-1H-1,2,3triazol-4-yl)methyl]amine) has not been used as a ligand in ATRC reactions, it has been reported as an excellent ligand for $\mathrm{Cu}(\mathrm{I})$ stabilisation in CuAAC reactions. ${ }^{11}$ Treating indole $\mathbf{1 2}$ with 2.2 equivalents of both $\mathrm{CuCl}$ and TBTA, afforded pentacycle 15 in $67 \%$ yield, after spontaneous elimination of $\mathrm{HCl}$. Attempts to reduce the amount of $\mathrm{CuCl} / \mathrm{TBTA}$ to $10 \mathrm{~mol} \%$ afforded only trace amounts of product presumably because of interference from the in situ generated $\mathrm{HCl}$ (see SI for full optimisation table).

With a successful route to the pentacyclic structure established, removal of the gem-dichloride group, that had been necessary for the ATRC, was now required (Scheme 4). Protodechlorination of both chlorine atoms and reduction of the imine in $\mathbf{1 5}$ was achieved in one step using activated zinc dust in superheated methanol with acetic acid as additive, giving pentacycle 1 in excellent yield. Chemoselective reduction of the amide in 1 was achieved using a one-pot, two-step reductive procedure. First Vaska's complex $\left(\mathrm{IrCl}(\mathrm{CO})\left(\mathrm{PPh}_{3}\right)_{2}, 5 \mathrm{~mol}\right.$ $\%)$ and stoichiometric amounts of the silane reductant TMDS (1,1,3,3-tetramethyldisiloxane) efficiently gave hemiaminal $\mathbf{1 7}$ after $1 \mathrm{~h}^{12}$ Subsequent addition of $\mathrm{MeOH}, \mathrm{NaBH}_{3} \mathrm{CN}$ and $\mathrm{AcOH}$ afforded the desired pentacyclic amine 18, which was confirmed by single crystal X-ray diffraction. ${ }^{13}$

In summary, we have developed a concise enantioselective synthesis of the pentacyclic (ABCDE) core of the Strychnos alkaloids. Our strategy was based upon using a key enantioselective organocatalysed enantioselective desymmetrisation to generate the morphan core containing three stereogenic centers in high enantio- and diastereoselectivity. Subsequent introduction of the indole motif was achieved using the Barluenga indolisation protocol. We identified TBTA as a new ligand for $\mathrm{Cu}(\mathrm{I})$ in ATRC and successfully used this system for a dearomatising cyclisation to give the C-ring, furnishing 
Scheme 4. Formation of the C-ring using an ATRC and subsequent chemoselective reduction of the amide moiety

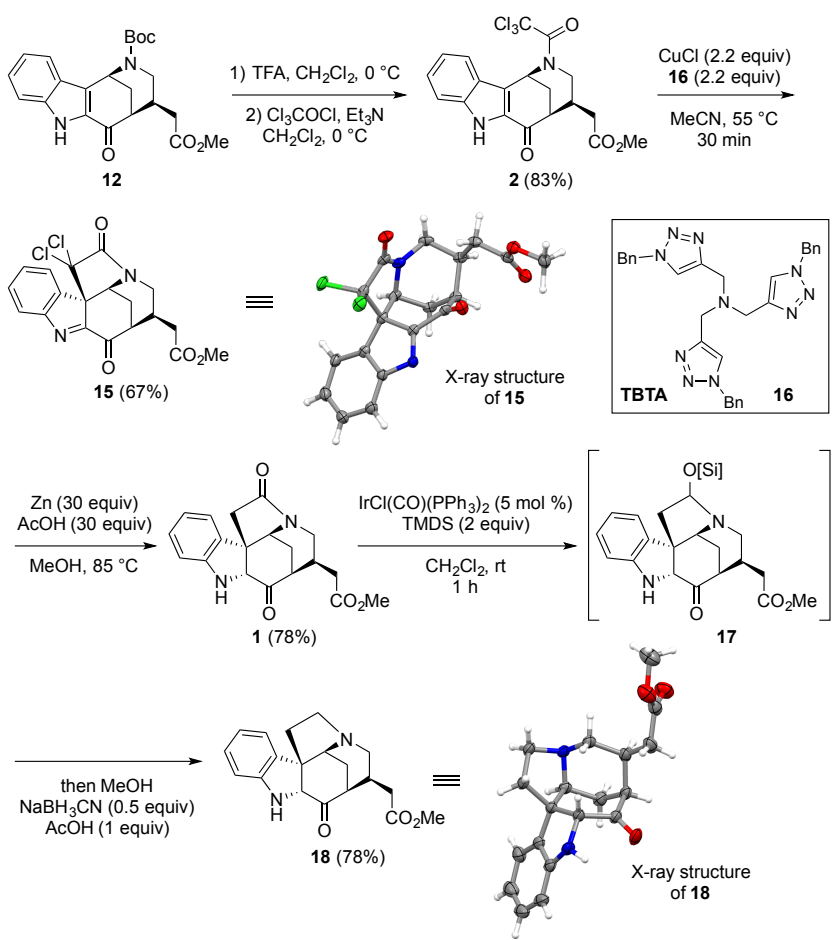

the pentacyclic core of the Strychnos alkaloids. Further studies towards the synthesis of strychnine and other Strychnos alkaloids are ongoing and will be reported in due course.

\section{ASSOCIATED CONTENT}

\section{Supporting Information}

The Supporting Information is available free of charge on the ACS Publications website.

Experimental procedures, spectroscopic and analytical data, NMR spectra (PDF) and X-ray data (CIF).

\section{AUTHOR INFORMATION}

\section{Corresponding Author}

* Email: darren.dixon@chem.ox.ac.uk

Notes

The authors declare no competing financial interest.

\section{ACKNOWLEDGMENT}

We gratefully acknowledge St John's College, Oxford and MSD, Hoddesdon, UK (for a studentship to A. D. G. Y). We also thank Ángel L. Fuentes de Arriba, Heyao Shi, Dr. Amber L. Thompson, Dr. Kirsten E. Christensen (Oxford Chemical Crystallography Service) for X-ray structure determination.

\section{REFERENCES}

(1) Woodward, R. B.; Cava, M. P.; Ollis, W. D.; Hunger, A.; Daeniker, H. U.; Schenker, K. J. Am. Chem. Soc. 1954, 76, 4749-4751.

(2) For a review of the syntheses of strychnine prior to 2000, see: (a) Bonjoch, J.; Solé, D. Chem. Rev. 2000, 100, 3455-3482. For a more recent review, see: (b) Cannon, J. S.; Overman, L. E. Angew. Chem. Int. Ed. 2012, 51, 4288-4311.

(3) For a review of dearomatisation strategies of indoles, see: Roche, S. P.; Youte Tendoung, J. J.; Tréguier, B. Tetrahedron 2015, 71, 3549-
3591.

(4) (a) Gammack Yamagata, A. D.; Datta, S.; Jackson, K. E.; Stegbauer, L.; Paton, R. S.; Dixon, D. J. Angew. Chem. Int. Ed. 2015, 54, 4899 4903. For a review of organocatalytic desymmetrisation, see: (b) Borissov, A.; Davies, T. Q.; Ellis, S. R.; Fleming, T. A.; Richardson, M. S. W.; Dixon, D. J. Chem. Soc. Rev. 2016, 45, 5474-5540.

(5) (a) Myers, A.; Tanaka, D.; Mannion, M. J. Am. Chem. Soc. 2002, 124, 11250-11251. (b) Tanaka, D.; Romeril, S. P.; Myers, A. G. J. Am. Chem. Soc. 2005, 127, 10323-10333. (c) Tanaka, D.; Myers, A. G. Org. Lett. 2004, 6, 433-436.

(6) (a) Söderberg, B. C.; Shriver, J. a. J. Org. Chem. 1997, 62, 5838-5845. (b) Scott, T. L.; Söderberg, B. C. G. Tetrahedron Lett. 2002, 43, 1621-1624. (c) Scott, T. L.; Yu, X.; Gorugantula, S. P.; CarreroMartínez, G.; Söderberg, B. C. G. Tetrahedron 2006, 62, 1083510842.

(7) (a) Barluenga, J.; Valdés, C. Chem. Commun. 2005, 4891-4901. (b) Barluenga, J.; Fernández, M. A.; Aznar, F.; Valdés, C. Chem. Eur. J. 2005, 11, 2276-2283. For the application of this reaction in the synthesis of (-)-nodulisporic acid D, see: (c) Zou, Y.; Melvin, J. E.; Gonzales, S. S.; Spafford, M. J.; Smith, A. B. J. Am. Chem. Soc. 2015, 137, 7095-7098.

(8) For the synthesis of the C-ring in the Strychnos and other alkaloids via a Pummerer cyclisation of the indole, see: (a) Amat, M.; Linares, A.; Bosch, J. J. Org. Chem. 1990, 55, 6299-6312. (b) Amat, M.; Bosch, J. J. Org. Chem. 1992, 57, 5792-5796. (c) Gracia, J.; Casamitjana, N.; Bonjoch, J.; Bosch, J. J. Org. Chem. 1994, 59, 3939-3951. (d) Bonjoch, J.; Catena, J.; Valls, N. J. Org. Chem. 1996, 61, 7106-7155. (e) Shimizu, S.; Ohori, K.; Arai, T.; Sasai, H.; Shibasaki, M. J. Org. Chem. 1998, 63, 7547-7551. For the synthesis of strychnine using the same strategy, see: (f) Ohshima, T.; Xu, Y.; Takita, R.; Shimizu, S.; Zhong, D.; Shibasaki, M. J. Am. Chem. Soc. 2002, 124, 14546-14547. (g) Ohshima, T.; Xu, Y.; Takita, R.; Shibasaki, M. Tetrahedron 2004, 60, 9569-9588. (h) For a related approach to the Strycnos alkaloid core, see: org.

(9) For a recent review of ATRC reactions, see: (a) Clark, A. J. Eur. J. Org. Chem. 2016, 2231-2243. For a review of radical cyclisations of trichloroacetamides, see: (b) Coussanes, G.; Vila, X.; Diaba, F.; Bonjoch, J. Synthesis 2017, 49, 1481-1499. For the synthesis of spiro-indoles via ATRC, see: (c) Stevens, C. V; Van Meenen, E.; Eeckhout, Y.; Vanderhoydonck, B.; Hooghe, W. Chem. Commun. 2005, 4827-4829.

(10) The ligands bipy, NMPI, TMEDA and TPMA, which are commonly used in conjunction with $\mathrm{CuCl}$ to mediate ATRC reactions were unsuccesful in the cyclisation of indole 12; see ATRC review above.

(11) For the use of TBTA as a $\mathrm{Cu}(\mathrm{I})$ stabilizing ligand in $\mathrm{CuAAC}$ reactions, see: (a) Chan, T. R.; Hilgraf, R.; Sharpless, K. B.; Fokin, V. V. Org. Lett. 2004, 6, 2853-2855. For a study of the $\mathrm{CuCl} / \mathrm{TBTA}$ complex, see: (b) Donnelly, P. S.; Zanatta, S. D.; Zammit, S. C.; White, J. M.; Williams, S. J. Chem. Commun. 2008, 2459-2461.

(12) For the chemoselective reduction of tertiary amides to aldenamides/enamines, see: (a) Motoyama, Y.; Aoki, M.; Takaoka, N.; Aoto, R.; Nagashima, H. Chem. Commun. 2009, 1574-1576. (b) Kobayashi, H.; Sasano, Y.; Kanoh, N.; Kwon, E.; Iwabuchi, Y. Eur. J. Org. Chem. 2016, 270-273. Chida and coworkers have reduced a tertiary amide to an amine using Vaska's catalyst and silane, followed by addition of TFA. These reaction conditions were unsuccesful in our case: (c) Nakayama, Y.; Maeda, Y.; Kotatsu, M.; Sekiya, R.; Ichiki, M.; Sato, T.; Chida, N. Chem. Eur. J. 2016, 22, 3300-3303.

(13) Single X-ray diffraction data for $\mathbf{1 5}$ and $\mathbf{1 8}$ were collected using a (Rigaku) Oxford Diffraction Supernova and a Nonius Kappa CCD diffractometer, respectively. Data for $\mathbf{1 5}$ were reduced using CrysAlisPro and solved using Superflip. Data for $\mathbf{1 8}$ were reduced using DENZO/SCALEPACK [Otwinowski, Z.; Minor, W. Processing of X-ray Diffraction Data Collected in Oscillation Mode, Methods Enzymol. (1997), 276, Eds C. W. Carter, R. M. Sweet, Academic Press] and solved using Superflip [Palatinus, L.; Chapuis, G. J. Appl. Cryst. 2007, 40, 786] before within CRYSTALS [Betteridge, P. W.; Carruthers, J. R.; Cooper, K. Prout, \& D. J. Watkin, J. Appl. Cryst., 2003, 36, 1487; R. I. Cooper, R. I.; Thompson, A. L.; Watkin, D. J. J. Appl. Cryst. 2010, 43, 1100]. Full crystallographic data (in CIF format) is available as ESI and has been deposited with the Cambridge Crystallographic Data Centre (reference code CCDC 1535935 \& 1535936 for $\mathbf{1 5}$ and $\mathbf{1 8}$, respectively). 